ARTICLE

\title{
Synthesis and X-ray characterization of $15-$ and 16-vertex closo-carboranes
}

\author{
Fangrui Zheng (10 ${ }^{1,2}$, Tsz Hin Yui ${ }^{1,2}$, Jiji Zhang $^{1} \&$ Zuowei Xie (iD) ${ }^{1 凶}$
}

Carboranes are a class of carbon-boron molecular clusters with three-dimensional aromaticity, and inherent robustness. These endowments enable carboranes as valuable building blocks for applications ranging from functional materials to pharmaceuticals. Thus, the chemistry of carboranes has received tremendous research interest, and significant progress has been made in the past decades. However, many attempts to the synthesis of carboranes with more than 14 vertices had been unsuccessful since the report of a 14-vertex carborane in 2005. The question arises as to whether these long sought-after molecules exist. We describe in this article the synthesis and structural characterization of 15- and 16-vertex closocarboranes as well as 16-vertex ruthenacarborane. Such a success relies on the introduction of silyl groups to both cage carbons, stabilizing the corresponding nido-carborane dianions and promoting the capitation reaction with $\mathrm{HBBr}_{2} \cdot \mathrm{SMe}_{2}$. This work would shed some light on the preparation of carboranes with 17 vertices or more, and open the door for studying supercarborane chemistry.

\footnotetext{
${ }^{1}$ Department of Chemistry and State Key Laboratory of Synthetic Chemistry, The Chinese University of Hong Kong, Shatin, New Territories, Hong Kong, China.

${ }^{2}$ These authors contributed equally: Fangrui Zheng, Tsz Hin Yui. ${ }^{凶}$ email: zxie@cuhk.edu.hk
} 
C arboranes are a class of carbon-boron molecular clusters with $3 \mathrm{D}$ aromaticity. They are finding a wide variety of applications as functional building blocks in the supramolecular design, medicine, catalysts, nanomaterials, and more ${ }^{1,2}$. These applications would be benefitted from higher nuclearity clusters containing large numbers of boron atoms. Thus, the chemistry of carboranes has attracted tremendous attention, particularly in the catalytic selective functionalization of carboranes $^{1,3-11}$ and polyhedral expansion for the synthesis of supercarboranes (carboranes with more than 12 vertices) ${ }^{12-14}$.

In contrast to the extensively studied icosahedral $o$-carboranes that have dominated the carborane chemistry for over half a century ${ }^{1,15,16}$, has considerable progress been made in the chemistry of supercarboranes only since $2003^{12}$. Such a breakthrough relied on the use of relatively weaker reducing compounds, CAd (carbon atoms-adjacent) nido-carborane dianions or arachno-carborane tetraanions ${ }^{17}$, as starting materials for polyhedral expansion reactions ${ }^{18,19}$. A number of 13 - and 14vertex closo-carboranes were prepared and structurally characterized $^{20-29}$. They showed some unique characteristics. For example, a 13-vertex closo-carborane accepted one electron to give a stable carborane radical anion with $[2 n+3]$ framework electrons ${ }^{30,31}$; it also reacted with various nucleophiles to afford the cage carbon and/or cage boron extrusion products closo$\mathrm{CB}_{11}^{-}$, nido- $\mathrm{CB}_{10}{ }^{-}$, closo- $\mathrm{CB}_{10}{ }^{-}$, and closo- $\mathrm{C}_{2} \mathrm{~B}_{10}$, depending on the nature of the nucleophiles ${ }^{32-35}$. Insertion of a metal fragment into a 14-vertex CAd nido-carborane was successful, resulting in the isolation and structural characterization of a 15-vertex metallacarborane 1,4- $\left(\mathrm{CH}_{2}\right)_{3}-7$ - $(p$-cymene $)-7,1,4-\mathrm{RuC}_{2} \mathrm{~B}_{12} \mathrm{H}_{12}{ }^{23}$. However, the reactions of CAd [nido- $\left(\mathrm{CH}_{2}\right)_{3} \mathrm{C}_{2} \mathrm{~B}_{12} \mathrm{H}_{12}$ ] $\mathrm{Na}_{2}$ with haloboranes $\mathrm{RBX}_{2}$ under different reaction conditions did not afford any 15-vertex closo-carborane, rather generated a structural isomer of CAd 14-vertex closo-carborane along with some inseparable very polar boron-containing species ${ }^{23}$. These results indicated that redox reaction proceeded in the system, in which nido-carborane was oxidized to the corresponding closo-species. To suppress such redox reactions and promote the capping reaction, a 14-vertex nido-carborane with lower reducing power is necessary.

It was documented that silyl groups can stabilize carboanions and the stabilization is approximately additive for the number of silyl groups ${ }^{36}$. We then speculated that the introduction of silyl groups to both cage carbon vertices should significantly stabilize the corresponding nido-carborane dianions, so as to lower their reducing power. On the other hand, our experimental and theoretical results indicate that CAp (carbon atoms-apart) closocarboranes are thermodynamically more stable than the corresponding CAd closo-species ${ }^{37}$. For instance, CAp 15-vertex carborane is calculated to be thermodynamically more stable over CAd isomer by $22.4 \mathrm{kcal} / \mathrm{mol}^{37}$. In view of the role of silyl groups and extra stability of CAp supercarboranes, we initiated a research program to prepare supercarboranes using $1,2-\left(\mathrm{R}_{3} \mathrm{Si}\right)_{2}$ $1,2-\mathrm{C}_{2} \mathrm{~B}_{10} \mathrm{H}_{10}$ as starting materials.

In this work, we report the synthesis and structural characterization of CAp 15- and 16-vertex closo-carboranes as well as 16 -vertex ruthenacarborane. The results indicate that they are thermodynamically very stable.

\section{Results and discussion}

15-Vertex closo-carborane. Reduction of $1,2-\left(\mathrm{RMe}_{2} \mathrm{Si}\right)_{2}-1,2-$ $\mathrm{C}_{2} \mathrm{~B}_{10} \mathrm{H}_{10}[\mathrm{R}=\mathrm{Me}(\mathbf{1 a}), \mathrm{Ph}(\mathbf{1} \mathbf{b})]$ with an excess amount of finely cut sodium metal in THF at room temperature gave presumably CAp nido-carborane salts $\left[\left\{7,9-\left(\mathrm{RMe}_{2} \mathrm{Si}\right)_{2}-7,9-\mathrm{C}_{2} \mathrm{~B}_{10} \mathrm{H}_{10}\right\}\right.$ $\left.\left\{\mathrm{Na}_{2}(\mathrm{THF})_{x}\right\}\right]^{38,39}$. Treatment of these salts with 2 equiv. of $\mathrm{HBBr}_{2} \cdot \mathrm{SMe}_{2}$ in dimethoxyethane (DME) from -78 to $25^{\circ} \mathrm{C}$ afforded, after column chromatographic separation, CAp 13vertex closo-carboranes $1,12-\left(\mathrm{RMe}_{2} \mathrm{Si}\right)_{2}-1,12-\mathrm{C}_{2} \mathrm{~B}_{11} \mathrm{H}_{11} \quad[\mathrm{R}=\mathrm{Me}$ (2a), $\mathrm{Ph}(\mathbf{2 b})]$ in $20-29 \%$ isolated yields. Their ${ }^{11} \mathrm{~B}$ NMR spectra exhibited a pattern of 1:2:1:3:3:1 ranging from $\delta=15$ to -17 ppm. Single-crystal X-ray analyses confirm that the cage carbons are located in 1- and 12-positions, respectively, in both $\mathbf{2 a}$ and $\mathbf{2 b}$ (Fig. 1).

Treatment of 2 with an excess amount of finely cut sodium metal in THF at room temperature, followed by the reaction with 3 equiv. of $\mathrm{HBBr}_{2} \cdot \mathrm{SMe}_{2}$ in $\mathrm{CH}_{2} \mathrm{Cl}_{2}$ (DCM) from -78 to $25^{\circ} \mathrm{C}$ afforded, after column chromatographic separation, CAp 14vertex closo-carboranes 2,9- $\left(\mathrm{RMe}_{2} \mathrm{Si}\right)_{2}-2,9-\mathrm{C}_{2} \mathrm{~B}_{12} \mathrm{H}_{12} \quad[\mathrm{R}=\mathrm{Me}$ (3a), $\mathrm{Ph}(3 \mathbf{b})]$ in $15-20 \%$ isolated yields (Fig. 1). The ${ }^{11} \mathrm{~B}$ NMR spectra of 3 exhibited a pattern of 2:4:4:2, ranging from $\delta=10$ to $-20 \mathrm{ppm}$. Their solid-state structures were further confirmed by single-crystal X-ray analyses, showing that they adopt a bicapped hexagonal antiprismatic geometry as that of 2,9- $\mathrm{Me}_{2}-2,9$ $\mathrm{C}_{2} \mathrm{~B}_{12} \mathrm{H}_{12}{ }^{27}$, with two cage carbons being located at 2- and 9positions.

Compounds 3 were treated with an excess amount of finely cut sodium metal in THF, followed by the reaction with 3 equiv. of $\mathrm{HBBr}_{2} \cdot \mathrm{SMe}_{2}$ from -78 to $25^{\circ} \mathrm{C}$ in $\mathrm{CH}_{2} \mathrm{Cl}_{2}$ gave, after column chromatographic separation, 1,14- $\left(\mathrm{RMe}_{2} \mathrm{Si}\right)_{2}-1,14-\mathrm{C}_{2} \mathrm{~B}_{13} \mathrm{H}_{13}$ $[\mathrm{R}=\mathrm{Me}(\mathbf{4 a}), \mathrm{Ph}(\mathbf{4 b})]$ in $3-8 \%$ isolated yields (Fig. 1). Their ${ }^{11} \mathrm{~B}$ NMR spectra showed a pattern of $2: 4: 4: 1: 2$ spanning the range $\delta=16$ to $-21 \mathrm{ppm}$. Single-crystal X-ray analyses show that 4b adopts a closo structure with 26 triangulated faces and 32 framework electrons. It has an approximate $D_{3 \mathrm{~h}}$ symmetry with a $C_{3}$ axis passing through the centers of $\mathrm{C}(1) \mathrm{B}(2) \mathrm{B}(3)$ and $\mathrm{B}(13) \mathrm{C}$ (14) $\mathrm{B}(15)$ trigonal planes if omitting two dimethylphenylsilyl (DMPS) groups and the differentia among boron and carbon atoms. The two 6-coordinate cage carbons are located at 1-, 14positions, respectively, which is the second stable CAp isomer predicted by DFT results ${ }^{37}$. There are three 7 -coordinate $[\mathrm{B}(7), \mathrm{B}$ (8) and $\mathrm{B}(9)]$, and ten 6-coordinate boron atoms.

16-Vertex ruthenacarborane. Reduction of $4 a$ with an excess amount of finely cut sodium metal in THF at room temperature, followed by interaction with 0.5 equiv. of $\left[(p \text {-cymene }) \mathrm{RuCl}_{2}\right]_{2}$ in THF from -30 to $25^{\circ} \mathrm{C}$ afforded, after column chromatographic separation, a 16-vertex ruthenacarborane 9,11- $\left(\mathrm{Me}_{3} \mathrm{Si}\right)_{2}-1-(p$ cymene)-1,9,11- $\mathrm{RuC}_{2} \mathrm{~B}_{13} \mathrm{H}_{13}(\mathbf{5} \mathbf{R u})$ in $38 \%$ isolated yield as yellow crystals. Its ${ }^{11} \mathrm{~B}$ NMR spectrum exhibited a 2:2:2:1:4:2 pattern in the range $\delta=0.1$ to $-28.2 \mathrm{ppm}$, which was very different from that of $\mathbf{4 a}$. Single-crystal X-ray analyses revealed that $\mathbf{5 R \mathbf { R }}$ adopts a closo structure with 26 triangular and one rhombus faces, in which the $\mathrm{Ru}$ atom is $\eta^{6}$-bonded to a six-membered $\mathrm{B}_{6}$ ring with an average $\mathrm{Ru}-\mathrm{B}$ distance of 2.274(3) $\AA$ (Fig. 1) ${ }^{40,41}$. This measured value is very close to that of $2.247(3) \AA$ in $1,4-\left(\mathrm{CH}_{2}\right)_{3}-7-(p$ cymene)-7,1,4- $\mathrm{RuC}_{2} \mathrm{~B}_{12} \mathrm{H}_{12}{ }^{23}$. The two 6-coordinate cage carbons are located in 9- and 11-positions, respectively. Careful examination of the X-ray structures of $\mathbf{4 b}$ and $\mathbf{5 R u}$ clearly indicated that significant cage rearrangement occurred during the reaction. A DSD (diamond-square-diamond) mechanism may be involved in such a skeletal rearrangement ${ }^{42}$.

16-Vertex closo-carborane. Treatment of $\mathbf{4 b}$ with an excess amount of finely cut sodium in THF at room temperature for 3 days, followed by reaction with 3 equiv. of $\mathrm{HBBr}_{2} \cdot \mathrm{SMe}_{2}$ in $\mathrm{CH}_{2} \mathrm{Cl}_{2}$ afforded, after column chromatographic separation, a CAp 16 -vertex closo-carborane $5 \mathbf{b}$ in $26 \%$ isolated yield as colorless crystals (Fig. 1). It is stable in air and soluble in common organic solvents such as $n$-hexane, acetone, $\mathrm{CH}_{2} \mathrm{Cl}_{2}$, and $\mathrm{CHCl}_{3}$. Attempts to prepare closo- $\mathrm{C}_{2} \mathrm{~B}_{14} \mathrm{H}_{16}$ by removing two silyl groups from $\mathbf{5 b}$ were not successful. 


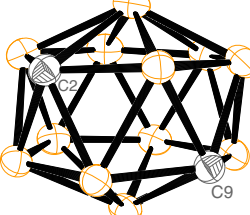

$3 b$

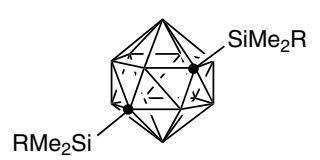

3a, $\mathrm{R}=\mathrm{Me}$

3b, $\mathrm{R}=\mathrm{Ph}$

14-vertex closo -carboranesa

1) $\mathrm{xs} \mathrm{Na}$

2) $\mathrm{HBBr}_{2}\left(\mathrm{SMe}_{2}\right)$

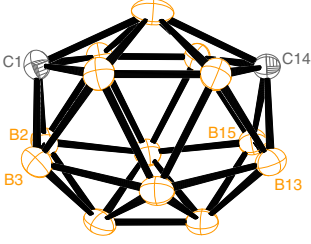

$4 b$

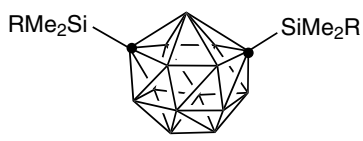

4a, $\mathrm{R}=\mathrm{Me}$

$4 \mathrm{~b}, \mathrm{R}=\mathrm{Ph}$

15-vertex closo -carboranes

$$
\begin{aligned}
& \text { 1) } \mathrm{xs} \mathrm{Na} \\
& \text { 2) } \mathrm{HBBr}_{2}\left(\mathrm{SMe}_{2}\right)
\end{aligned}
$$

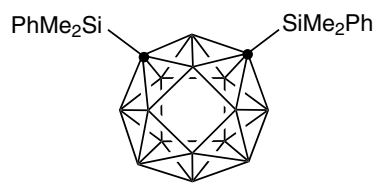

$5 b$

16-vertex closo -carborane

1) $x \mathrm{sa}$

2) $\mathrm{HBBr}_{2}\left(\mathrm{SMe}_{2}\right)$

1) $\mathrm{xs} \mathrm{Na}$

$$
\text { - }-\mathrm{C}
$$$$
\text { unmarked }-\mathrm{BH}
$$

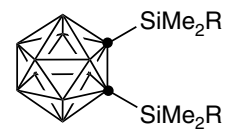

1a, $\mathrm{R}=\mathrm{Me}$

1b, $\mathrm{R}=\mathrm{Ph}$

1) $x \mathrm{Na}$

2) $\mathrm{HBBr}_{2}\left(\mathrm{SMe}_{2}\right)$

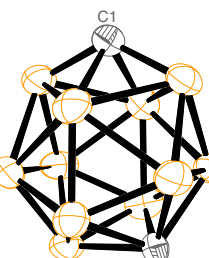

$2 b$

2) $0.5\left[(p \text {-cymene }) \mathrm{RuCl}_{2}\right]_{2}$

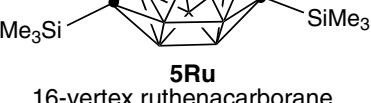

16-vertex ruthenacarborane

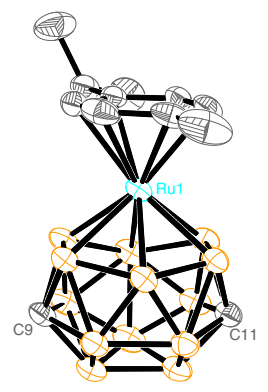

$5 R u$

Fig. 1 Synthesis of 13- to 16-vertex closo-carboranes and 16-vertex ruthenacarborane. Synthetic route along with the molecular structures of 13-vertex closo-carborane (2b), 14-vertex closo-carborane (3b), 15-vertex closo-carborane (4b), and 16-vertex ruthenacarborane (5Ru). For clarity, in the X-ray structures, all silyl moieties and hydrogen atoms have been omitted. Orange, B; grey, C.

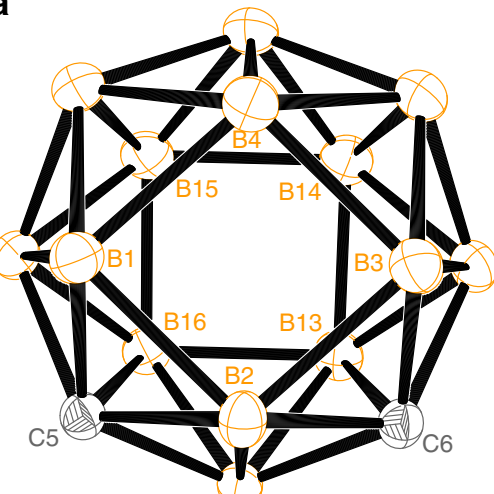

b

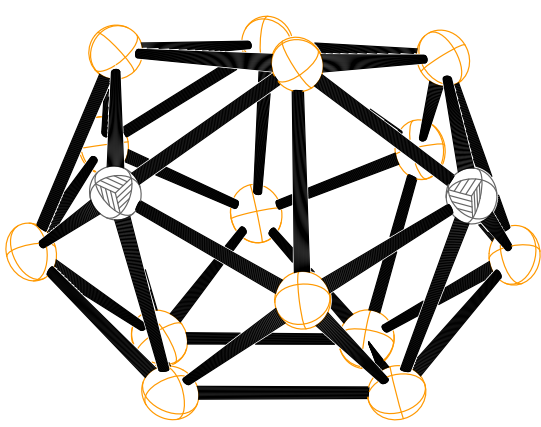

Fig. 2 Molecular structure of 16-vertex closo-carborane $\mathbf{5 b}$ in different view angles. a View down from the $B(1) B(2) B(3) B(4)$ face. $\mathbf{b} \vee$ iew down from the $\mathrm{C}(5)$ and $\mathrm{C}(6)$ atoms. Both silyl moieties and hydrogen atoms are omitted for clarity. Orange, B; grey, C. 

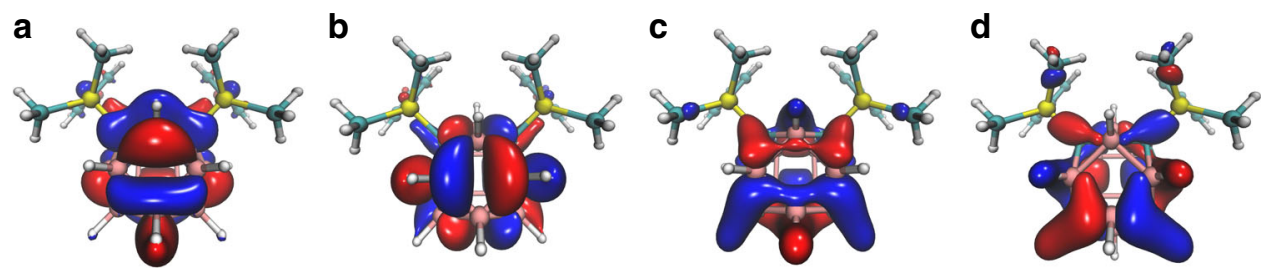

Fig. 3 Selected molecular orbitals of 16-vertex closo-carborane $5 \mathbf{b}$ calculated at the B3LYP/6-31G(d,p) level of theory. a LUMO $+1 . \mathbf{b} L U M O$. c HOMO4. d HOMO-5.

The ${ }^{11} \mathrm{~B}$ NMR spectrum of $5 \mathbf{b}$ displayed a pattern of 1:4:4:3:2 spanning the range $\delta=14.3$ to $-18.3 \mathrm{ppm}$. Its solidstate structure was confirmed by single-crystal X-ray analyses (Fig. 2). Compound 5b adopts a closo structure with 34 framework electrons, 24 triangular and two rhombus faces, in which the two 6coordinate cage carbons are located in the 5, 6-positions, respectively. If omitting two DMPS groups and the differentia among boron and carbon atoms, $5 \mathbf{b}$ has an approximate $D_{4 \mathrm{~d}}$ symmetry with a $C_{4}$ axis passing through the centers of $\mathrm{B}(1) \mathrm{B}(2) \mathrm{B}$ (3) $\mathrm{B}(4)$ and $\mathrm{B}(13) \mathrm{B}(14) \mathrm{B}(15) \mathrm{B}(16)$ faces (Fig. 2a). Such a geometry is predicted to be the third most stable isomer by DFT calculation ${ }^{37}$. It could also be viewed as a square-crown-square type of structure with two cage carbons located on the crown (Fig. 2b).

It has been well documented that closo-carboranes/closopolyhedral boranes are three-dimensional aromatic molecules, which have electrons delocalized through a set of orbitals tangential to the polyhedral surface ${ }^{43,44}$. The structural features of $\mathbf{4 b}$ and $\mathbf{5 b}$ were confirmed by density functional theory (DFT) calculations at the B3LYP level of theory (see computational details in the Supplementary Information and cartesian coordinates in Supplementary Data 1 and 2). The HOMO (highest occupied molecular orbital) is composed of the contribution of the $\pi$ orbitals of the phenyl rings from the $\mathrm{SiMe}_{2} \mathrm{Ph}$ groups (see Supplementary Figs. 8 and 9). The LUMO (lowest unoccupied molecular orbitals) exhibits anti-bonding characters of cage tangential orbitals. Figure 3 shows the LUMO, LUMO +1 , HOMO-4, and HOMO-5 orbitals of $\mathbf{5 b}$.

In summary, we have prepared and fully characterized 15- and 16-vertex closo-carboranes as well as 16-vertex ruthenacarborane. The results indicate that they are thermodynamically very stable. Such a success relies on the introduction of silyls onto the two cage carbons, stabilizing the corresponding nido-carborane dianions, and thus facilitating the capitation reaction. Following this strategy, if silyl groups would be introduced to cage boron atoms, it is anticipated that carboranes with 17 vertices or more would be prepared in the future as they are calculated to be thermodynamically more stable than 13 - and 15-vertex closocarboranes ${ }^{37}$. On the other hand, it is further anticipated that these superclusters may find applications in coordination chemistry/materials science in view of the recent development in this field ${ }^{45-48}$.

\section{Methods}

The synthetic protocol and the characterization of compounds $\mathbf{1 a}-\mathbf{4 a}, \mathbf{1 b}-\mathbf{5 b}$, and $\mathbf{5 R u}$ can be found in the Supplementary Information.

\section{Data availability}

CCDC 1997899 (2a), 1997900 (2b), 1997901 (3a), 1997902 (3b), 1997903 (4b), 1997904 (5b), and 1997905 (5Ru) contain the supplementary crystallographic data for this paper. These data can be obtained free of charge from The Cambridge Crystallographic Data Centre via www.ccdc.cam.ac.uk/data_request/cif.

Received: 25 June 2020; Accepted: 19 October 2020; Published online: 23 November 2020

\section{References}

1. Grimes, R. N. Carboranes 3rd edn (Elsevier, Oxford, UK, 2016).

2. Hosmane, N. S. Boron Science: New Technologies and Applications (CRC, Boca Raton, FL, 2011).

3. Quan, Y. \& Xie, Z. Controlled functionalization of o-carborane via transition metal catalyzed B-H activation. Chem. Soc. Rev. 48, 3660-3673 (2019).

4. Qiu, Z. Recent advances in transition metal-mediated functionalization of ocarboranes. Tetrahedron Lett. 56, 963-971 (2015).

5. Olid, D., Núñez, R., Viñas, C. \& Teixidor, F. Methods to produce B-C, B-P, B-N and B-S bonds in boron clusters. Chem. Soc. Rev. 42, 3318-3336 (2013).

6. Quan, Y., Qiu, Z. \& Xie, Z. Transition-metal-catalyzed selective cage B-H functionalization of o-carboranes. Chem. Eur. J. 24, 2795-2805 (2018).

7. Dziedzic, R. M. \& Spokoyny, A. M. Metal-catalyzed cross-coupling chemistry with polyhedral boranes. Chem. Commun. 55, 430-442 (2019).

8. Zhao, D. \& Xie, Z. Recent advances in the chemistry of carborynes. Coord. Chem. Rev. 314, 14-33 (2016)

9. Fisher, S. P. et al. Nonclassical applications of closo-carborane anions: from main group chemistry and catalysis to energy storage. Chem. Rev. 119, 8262-8290 (2019)

10. Qiu, Z., Ren, S. \& Xie, Z. Transition metal-carboryne complexes: synthesis, bonding, and reactivity. Acc. Chem. Res. 44, 299-309 (2011).

11. Scholz, M. \& Hey-Hawkins, E. Carbaboranes as pharmacophores: properties, synthesis, and application strategies. Chem. Rev. 111, 7035-7062 (2011).

12. Zhang, J. \& Xie, Z. Synthesis, structure, and reactivity of 13- and 14-Vertex Carboranes. Acc. Chem. Res. 47, 1623-1633 (2014).

13. Deng, L. \& Xie, Z. A journey from 12-vertex to 14-vertex carboranes and to 15-vertex metallacarboranes. Organometallics 26, 1832-1845 (2007).

14. Boyd, A. S. F. et al. Supraicosahedral (metalla)carboranes. Pure Appl. Chem. 75, 1325-1333 (2003).

15. Heying, T. L. et al. A new series of organoboranes. I. Carboranes from the reaction of decaborane with acetylenic compounds. Inorg. Chem. 2, 1089-1092 (1963).

16. Hawthorne, M. F. \& Wegner, P. A. The reconstruction of the 1,2dicarbaclovododecaborane(12) structure by boron-atom insertion with (3)1,2-dicarbollide ions. J. Am. Chem. Soc. 90, 896-901 (1968).

17. Xie, Z. Controlled synthesis of carbons-adjacent and-apart nido- and arachnocarborane anions and their metal complexes. Pure Appl. Chem. 75, 1335-1341 (2003).

18. Hawthorne, M. F. \& Dunks, G. B. Metallocarboranes that exhibit novel chemical features. Science 178, 462-471 (1972).

19. Dunks, G. B., McKown, M. M. \& Hawthorne, M. F. Probable formation of 13 atom polyhedral complexes containing $\mathrm{B}_{10} \mathrm{C}_{2} \mathrm{H}_{12}{ }^{2-}$ and cobalt. J. Am. Chem. Soc. 93, 2541-2543 (1971).

20. Burke, A. et al. Beyond the icosahedron: the first 13-vertex carborane. Angew. Chem. Int. Ed. 42, 225-228 (2003).

21. Deng, L., Chan, H.-S. \& Xie, Z. Synthesis, reactivity, and structural characterization of a 14-vertex carborane. Angew. Chem. Int. Ed. 44, 2128-2131 (2005).

22. Deng, L., Chan, H.-S. \& Xie, Z. Synthesis, structure, and reactivity of 13-vertex carboranes and 14-vertex metallacarboranes. J. Am. Chem. Soc. 128, 5219-5230 (2006).

23. Deng, L., Zhang, J., Chan, H.-S. \& Xie, Z. Synthesis and structure of 14- and 15-vertex ruthenacarboranes. Angew. Chem. Int. Ed. 45, 4309-4313 (2006).

24. McIntosh, R. D., Ellis, D., Rosair, G. M. \& Welch, A. J. A 15-vertex heteroborane. Angew. Chem. Int. Ed. 45, 4313-4316 (2006).

25. Zhang, J., Deng, L., Chan, H.-S. \& Xie, Z. Role of C,C'-linkage in the formation and stabilization of supercarboranes. Synthesis and structure of carbon-atomsapart 13-vertex carborane and 14-vertex metallacarborane. J. Am. Chem. Soc. 129, 18-19 (2007).

26. Roy, D. K. et al. Boron beyond the icosahedral barrier: a 16-vertex metallaborane. Angew. Chem. Int. Ed. 52, 3222-3226 (2013).

27. Zhang, J., Zheng, F. \& Xie, Z. Synthesis and characterization of 14-vertex carboranes. Organometallics 32, 7399-7406 (2013). 
28. Deng, L. \& Xie, Z. Advances in the chemistry of carboranes and metallacarboranes with more than 12 vertices. Coord. Chem. Rev. 251, 2452-2476 (2007).

29. Zhang, J. \& Xie, Z. Recent progress in the chemistry of supercarboranes. Chem. Asian J. 5, 1742-1757 (2010).

30. Fu, X., Chan, H.-S. \& Xie, Z. Synthesis and crystal structure of a 13-vertex carborane radical anion with $2 \mathrm{n}+3$ framework electrons. J. Am. Chem. Soc. 129, 8964-8965 (2007).

31. Zhang, J., Fu, X., Lin, Z. \& Xie, Z. Supercarborane radical anions with $2 n+3$ electron counts: a combined experimental and theoretical study. Inorg. Chem. 54, 1965-1973 (2015).

32. Zhang, J., Chan, H.-S. \& Xie, Z. Reaction of 13-vertex carboranes with nucleophiles: unprecedented cage-carbon extrusion and formation of monocarbacloso-dodecaborate anions. Angew. Chem. Int. Ed. 47, 9447-9449 (2008).

33. Zhang, J., Chan, H.-S. \& Xie, Z. Selective Cage boron/carbon extrusion reaction of 13-vertex carborane $\mu-1,2-\left(\mathrm{CH}_{2}\right)_{3}-1,2-\mathrm{C}_{2} \mathrm{~B}_{11} \mathrm{H}_{11}$ : formation of nido- $\mathrm{CB}_{10}$, closo- $\mathrm{CB}_{10}$, and closo- $\mathrm{C}_{2} \mathrm{~B}_{10}$ species. Chem. Commun. 47, 8082-8084 (2011).

34. Zhang, J. \& Xie, Z. Reaction of 13 -vertex carborane $\mu-1,2-\left(\mathrm{CH}_{2}\right)_{3}-1,2-$ $\mathrm{C}_{2} \mathrm{~B}_{11} \mathrm{H}_{11}$ with nucleophiles: scope and mechanism. Inorg. Chem. 51, 12976-12987 (2012).

35. Zhang, J. \& Xie, Z. Reaction of 13-vertex carborane $\mu-1,2-\left(\mathrm{CH}_{2}\right)_{4}-1,2$ $\mathrm{C}_{2} \mathrm{~B}_{11} \mathrm{H}_{11}$ with nucleophiles: linkage effect on product formation. Inorg. Chem. 52, 10677-10684 (2013).

36. Brinkman, E. A., Berger, S. \& Brauman, J. I. a-Silyl-substituent stabilization of carbanions and silyl anions. J. Am. Chem. Soc. 116, 8304-8310 (1994).

37. Zhang, J., Lin, Z. \& Xie, Z. DFT studies on structures, stabilities, and electron affinities of closo-supercarboranes $\mathrm{C}_{2} \mathrm{~B}_{\mathrm{n}-2} \mathrm{H}_{\mathrm{n}}(\mathrm{n}=13-20)$. Organometallics 34, 5576-5588 (2015).

38. Dunks, G. B., Wiersema, R. J. \& Hawthorne, M. F. Chemical and structura studies of the $\mathrm{B}_{10} \mathrm{C}_{2} \mathrm{H}_{12}{ }^{2-}$ ions produced from icosahedral $\mathrm{B}_{10} \mathrm{C}_{2} \mathrm{H}_{12}$ carboranes. J. Am. Chem. Soc. 95, 3174-3179 (1973).

39. Chui, K., Li, H.-W. \& Xie, Z. Synthesis and structural characterization of closo-exo, exo-nido, and pseudocloso group 1 carborane compounds of the $\mathrm{C}_{2} \mathrm{~B}_{10}$ system. Organometallics 19, 5447-5453 (2000).

40. Roy, D. K. et al. Supraicosahedral polyhedra in metallaboranes: synthesis and structural characterization of 12-, 15-, and 16-vertex rhodaboranes. Inorg. Chem. 52, 6705-6712 (2013)

41. Attia, A. A. A., Lupan, A., King, R. B. \& Ghosh, S. The tetracapped truncated tetrahedron in 16-vertex tetrametallaborane structures: spherical aromaticity with an isocloso rather than a closo skeletal electron count. Phys. Chem. Chem. Phys. 21, 22022-22030 (2019).

42. Lipscomb, W. N. Framework rearrangement in boranes and carboranes. Science 153, 373-378 (1966).

43. King, R. B. Three-dimensional aromaticity in polyhedral boranes and related molecules. Chem. Rev. 101, 1119-1152 (2001).

44. Zhai, H.-J., Kiran, B., Li, J. \& Wang, L.-S. Hydrocarbon analogues of boron clusters-planarity, aromaticity and antiaromaticity. Nat. Mater. 2, 827-833 (2003).

45. Spokoyny, A. M. et al. A coordination chemistry dichotomy for icosahedral carborane-based ligands. Nat. Chem. 3, 590-596 (2011).
46. Keener, M. et al. Redox-switchable carboranes for uranium capture and release. Nature 577, 652-655 (2020)

47. Yan, H. et al. Sterically controlled mechanochemistry under hydrostatic pressure. Nature 554, 505-510 (2018).

48. Jung, D. et al. A molecular cross-linking approach for hybrid metal oxides. Nat. Mater. 17, 341-348 (2018)

\section{Acknowledgements}

This work was supported by grants from the Research Grants Council of the Hong Kong Special Administration Region (Project Nos. 14306519 and 14305918).

\section{Author contributions}

Z.X. directed and conceived this project. F.Z. and T.H.Y. conducted the experiments J.Z. did the theoretical work. All authors discussed the results and wrote the manuscript.

\section{Competing interests}

The authors declare no competing interests.

\section{Additional information}

Supplementary information is available for this paper at https://doi.org/10.1038/s41467 020-19661-5.

Correspondence and requests for materials should be addressed to Z.X.

Peer review information Nature Communications thanks Vincent LaVallo and the other, anonymous, reviewer(s) for their contribution to the peer review of this work.

Reprints and permission information is available at http://www.nature.com/reprints

Publisher's note Springer Nature remains neutral with regard to jurisdictional claims in published maps and institutional affiliations.

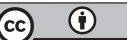

Open Access This article is licensed under a Creative Commons Attribution 4.0 International License, which permits use, sharing, adaptation, distribution and reproduction in any medium or format, as long as you give appropriate credit to the original author(s) and the source, provide a link to the Creative Commons license, and indicate if changes were made. The images or other third party material in this article are included in the article's Creative Commons license, unless indicated otherwise in a credit line to the material. If material is not included in the article's Creative Commons license and your intended use is not permitted by statutory regulation or exceeds the permitted use, you will need to obtain permission directly from the copyright holder. To view a copy of this license, visit http://creativecommons.org/ licenses/by/4.0/.

(c) The Author(s) 2020 